\title{
EDITORIAL
}

\section{Macrophages and tumor angiogenesis}

\section{Leukemia (2007) 21, 2085-2089; doi:10.1038/sj.leu.2404900}

Angiogenesis plays a crucial role in the cancerogenesis, growth and progression of human solid and hematological tumors. ${ }^{1,2}$ The passage from the preangiogenic phenotype to the angiogenic phenotype, referred to as the 'angiogenic switch', allows the formation of a neovasculature that is indispensable for tumor growth and metastatic dissemination. ${ }^{3}$

In 1889, the English surgeon Stephen Paget published his 'seed and soil' explanation of nonrandom pattern of metastasis, and was the first to suggest that interactions between tumor cells and host cells in the microenvironment are critical in regulating tumorigenesis. ${ }^{4}$ Certain favored tumor cells (the 'seed'), he said, had a specific affinity for the growth-enhancing milieu within specific organs (the 'soil'), and hence metastasis only occurred when the 'seed' and 'soil' were compatible. ${ }^{5}$ The importance of several components of the 'soil' in regulating tumor growth has since been emphasized: (1) the extracellular matrix; (2) stromal cells and their growth factors and inhibitors; (3) microvessels and angiogenic factors; and (4) inflammatory cells.

The tumor microenvironment is a complex system of many cell type, including endothelial cells and their precursors, pericytes, smooth-muscle cells, fibroblasts, neutrophils, eosinophils, basophils, mast cells, T, B and natural killer lymphocytes, and antigen-presenting cells, such as macrophages and dendritic cells, which communicate through a complex network of intercellular signaling pathways that are mediated by surface adhesion adhesion molecules, cytokines and their receptors.

Tumor angiogenesis result not only from the interaction of cancer cells with endothelial cells, but surrounding inflammatory cells have also a crucial role in directing the neoformation of blood vessels.

Macrophages are derived from CD34-positive bone marrow progenitors that continually proliferate and shed their progeny in the bloodstream as promonocytes. They then develop into monocyte and extravasate into tissues where they differentiate into a specific type of 'resident' tissue macrophage. ${ }^{6}$ Metchnikoff was the first person in 1893 to use the term 'macrophage' to describe a large cell able to take up microorganisms. ${ }^{7}$ The phenotype of these fully differentiated, resident macrophages can vary markedly within tissues, from that of microglial cells in the brain, Kupffer cells in the liver, alveolar macrophages in the lung and Langerhans cells in the skin. Resident macrophages share a set of common functions, including their ability to intervene against microbial infections, to regulate normal cell turnover and tissue remodeling, and to help repair sites of injury. ${ }^{6}$

Almost any local disturbance of tissue normality, be it infection, normal cell turnover or wounding, immune response or malignancy, caused rapid recruitment of macrophages. Recruited macrophages exhibit many phenotypic differences from resident tissue macrophages. The generic term, 'macrophages activation' is commonly used to describe this process, but the nature of an 'activated macrophage' population depends upon both the nature of the recruiting stimulus and the location.
It is now well established that the functional domain of the macrophage extends far beyond its originally recognized role as a scavenger cell. Its rich array of secretory products, anatomic diversity and functional heterogeneity is unmatched by any other cell type. As a result of this remarkable versatility, the macrophage is able to influence every facet of the immune response and inflammation as well as playing a central role in the etiology and/or pathogenesis of a number of disease processes.

Monocyte differentiated into polarized macrophage subset when exposed to different cytokine milieu. ${ }^{8}$ In the presence of granulocyte-macrophage colony-stimulating factor (GM-CSF), interferon gamma (IFN- $\gamma$ ), lipopolysaccharide and other microbial products, monocyte differentiate into M1 macrophage. In the presence of macrophage colony-stimulating factor (M-CSF), interleukin (IL)-4, IL-13, IL-10, immunosuppressive agents (corticosteroids, vitamin $\mathrm{D}_{3}$, prostaglandins) monocytes differentiate into M2 macrophages, involved in tumor angiogenesis.

Firstly in 1863, Rudolf Virchow noticed the infiltration of leukocytes into malignant tissues and suggested that cancers arise at regions of chronic inflammation. ${ }^{9}$ Leukocytes that do reach the tumor often remain localized in the tumor periphery or stroma and are often not able to exert strong antitumor activity. ${ }^{10}$ Both mouse and human tumors produce tumorderived chemotactic factors capable of stimulating monocyte migration. ${ }^{11}$

Tumor-associated macrophages (TAMs) derived from circulating monocytes and are recruited at the tumor site by a tumor-derived chemotactic factor from monocytes, originally described by Bottazzi et al., ${ }^{12}$ and later identified as the chemokine CCL2/MCP-1. ${ }^{13,14}$ When exposed to vascular endothelial growth factor (VEGF) ${ }^{15}$ or to brief ischemia, ${ }^{16}$ endothelial cells synthesize MCP-1 and the extent of MCP-1 expression in human cancers correlated with both TAM infiltration and tumor malignancy in human melanoma, in Kaposi sarcoma cell lines and in human tumor cell lines of epithelial origin such as breast, colon and ovary. ${ }^{17}$ Moreover, MCP-1 is angiogenic when implanted into the rabbit cornea, where it exerted a potency similar to VEGF. ${ }^{18} \mathrm{MCP}-1$ expression has been shown to correlate significantly with levels of VEGF, tumor necrosis factor- $\alpha$ (TNF- $\alpha$ ) and IL-8. ${ }^{19-21}$

The expression of CCL5/RANTES is elevated in breast tumor cells synergistically by IFN- $\gamma$ and TNF- $\alpha$, regulating monocyte migration into tumor sites and stimulate them to secrete matrix metalloproteinase (MMP)-9 and MMP-19. ${ }^{22,23}$

CSF and GM-CSF are commonly produced in a range of different tumor types and are chemotactic for macrophages in vitro. ${ }^{24}$ Transplanted mouse tumors transfected with the GM-CSF gene exhibit increased TAM infiltration ${ }^{25}$ and genetic deletion of CSF-1 in the PyMT mouse model of breast cancer significantly decreased TAM infiltration and attenuated tumor progression to metastasis. ${ }^{26}$ Increased expression of GM-CSF has been found in human breast, endometrial and ovarian tumors ${ }^{27}$ and high GM-CSF expression is associated with high TAM accumulation in breast carcinomas. ${ }^{28}$ Also VEGF is chemotactic for monocytes via VEGFR-1. ${ }^{29,30}$ 
TAM expresses and releases epidermal growth factor (EGF), fibroblast growth factor-2 (FGF-2), ${ }^{31,32}$ transforming growth factor- $\alpha$ and $-\beta$ (TGF- $\alpha$ and $-\beta),{ }^{33-35}$ VEGF, ${ }^{36}$ TNF- $\alpha^{37}$ IL- $1,{ }^{38}$ IL-6, IL- $8,{ }^{39}$ platelet-activating factor ${ }^{40}$ platelet-derived growth factor (PDGF) ${ }^{41}$ G-CSF and GM-CSF. ${ }^{42}$ thymidine phosphorylase $^{43}$ and chemokines, such as CCL2. ${ }^{44}$ TAMs produce, besides, angiogenic factors, angiostatic molecules such as thrombospondin- $1,{ }^{45} \mathrm{IL}-12,{ }^{46} \mathrm{IL}-18^{47}$ and MMP-12. ${ }^{48}$ TAMs can produce angiogenesis regulators and may also induce tissue remodeling by producing various proteinase activators and inhibitors that may destroy the integrity of the basement membrane and extracellular matrix, liberating matrix-bound factors, including MMP-2, MMP-9, MMP-12 and cyclooxygenase-2 (COX-2). ${ }^{49-51}$ TAM production of MMP-9 has been shown to be crucial for angiogenesis in a human papillomavirus-16induced model of cervical carcinogenesis. In this model, inhibition of MMP-9 in macrophages blocked the release of VEGF and thereby inhibited angiogenesis and tumor growth. ${ }^{52}$ Inhibition of CSF-1 function in human tumors xenografted into immunocompromised mice reduced their growth and this was correlated with poor macrophage recruitment and reduced angiogenesis due to a depletion of VEGF.

TAMs accumulate in hypoxic regions of tumors and hypoxia triggers a proangiogenic program in these cells. TAM adaptation to hypoxia, which is achieved by the increased expression of hypoxia-inducible and proangiogenic genes, such as VEGF, FGF-2 and CXCL8, as well as glycolytic enzymes, whose transcriptions are controlled by the transcription factors hypoxiainducible factors 1 and 2 (HIF-1 and -2). ${ }^{53}$ Increased number of TAMs in hypoxic regions may promote tumor progression in part by stimulating levels of angiogenesis, such as occurring in breast carcinoma. 54

White et al. ${ }^{55}$ used adenoviral infection to overexpress HIF-2 in human macrophages and found it to be the primary inducer of genes encoding angiogenic cytokines in these genes. Macrophages also upregulates VEGF and other proangiogenic factors in response to hypoxia. TAMs express VEGF almost exclusively in avascular and perinecrotic areas of human breast carcinoma. ${ }^{56}$

Macrophages also synthesize increased levels of MMP-7 when exposed to hypoxia in vitro and in an avascular area of human tumors. ${ }^{57}$ MMP-7 is known to stimulate endothelial cell proliferation and migration. ${ }^{58}$

A complementary DNA array study has identified upregulation of messenger encoding $>30$ proangiogenic genes in primary macrophages exposed to hypoxia, including CXCL8, angiopoietin, COX-2 and other factors. ${ }^{55}$

Bingle et al. ${ }^{59}$ found that when macrophages are co-cultured in vitro with human tumor spheroids, they infiltrate deep into the central, hypoxic areas of these structures. The release of VEGF by macrophage-infiltrated spheroids was significantly higher than that seen for noninfiltrated spheroids. This increase translated into a significant stimulation of angiogenesis in vivo when implanted into microcirculation window chambers on the flags of nude mice for 3 days. ${ }^{59}$

Evans ${ }^{60,61}$ has shown that mice depleted of macrophages by whole-body X-irradiation or azathioprine administered before or after implantation of a syngeneic fibrosarcoma showed a delay in the appearance of tumors, and a marked reduction in tumor vascularization. Mostafa et al. ${ }^{62,63}$ and Stenzinger et al. ${ }^{64}$ showed that vascularization of several human tumor cell lines grown on the chorioallantoic membrane of the chick embryo or subcutaneously in nude mice occurred coincidentally with mononuclear cell infiltration at the tumor site.

Polverini and Leibovich ${ }^{65}$ isolated macrophages from a transplantable rat fibrosarcoma and examined them and their serum-free conditioned media for angiogenic activity in rat corneas. Results showed that TAM and their conditioned media were potently angiogenic in vivo and stimulated proliferation of bovine aortic endothelial cells in culture. Moreover, when TAMs were combined with tumor cells at a concentration equivalent to the number of macrophages originally present in the tumor, there was a marked enhancement of tumor neovascularization and growth. Polverini and Leibovich ${ }^{66}$ reported that hamsters bearing chemical carcinogen-induced squamous-cell carcinomas showed a marked reduction in the thymidine incorporation by endothelial cells and neovascularization of tumors when treated with low doses of steroids and anti-macrophage serum.

In the mouse model of breast cancer caused by the mammary epithelial cell restricted expression of the Polyoma middle $\mathrm{T}$ oncoprotein (PyMT mice) infiltration of TAM in primary tumors is positively associated with tumor progression to malignancy. ${ }^{26}$ Depletion of macrophages in this model severely delayed tumor progression and reduced metastasis, whereas an increase in macrophage infiltration remarkably accelerated these processes. By using the PyMT-induced mouse mammary tumors, Lin et al. ${ }^{67}$ have characterized the development of the vasculature in mammary tumors during their progression to malignancy. They have shown that both angiogenic switch and the progression to malignancy are regulated by infiltrated macrophages in the primary mammary tumors. Moreover, inhibition of the macrophage infiltration into the tumor delayed the angiogenic switch and malignant transition, whereas genetic reduction of the macrophage population specifically in these tumors rescued the vessel phenotype. Finally, premature induction of macrophage infiltration into premalignant lesions promoted an early onset of the angiogenic switch independent of tumor progression. ${ }^{67}$

De Palma et al. ${ }^{68}$ have shown that a subset of monocytes that express the angiopoietin receptor Tie-2 are inducers of angiogenesis in both spontaneous and orthotopic tumor models. Knockout of these Tie-2-expressing cells in vivo markedly reduced angiogenesis in human glioma xenografts and prompted tumor regression.

A relationship between the macrophage content of tumors, the rate of tumor growth and the extent of their vascularization has been shown in several tumors, including breast carcinoma where TAM presence focally in large numbers correlates with a high level of angiogenesis and with poor prognosis, decreased relapse-free and overall survival of the patients, ${ }^{69,70}$ malignant uveal melanoma, ${ }^{71}$ glioma, ${ }^{72}$ squamous-cell carcinoma of the esophagus, ${ }^{73}$ bladder carcinoma ${ }^{74}$ and prostate carcinoma. ${ }^{75}$ In lung cancer, TAM may favor tumor progression by contributing to stroma formation and angiogenesis through their release of PDGF in conjunction with TGF- $\beta-1$ production by cancer cells. $^{76}$

Monocytes/macrophages display a high degree of plasticity, as shown by their ability to transdifferentiate into endothelial cells in vitro and in vivo. ${ }^{77-85} \mathrm{CD} 14^{+}$mononuclear cells have been used as the starting population for cultivation of endothelial progenitor cells (EPCs). ${ }^{77}$ Cultivated EPC grown from different starting populations, including peripheral blood mononuclear cells, have been shown to express endothelial markers such as von Willebrand factor, VEGFR-2, VE-cadherin, CD156 and CD31. ${ }^{86}$ Monocytes coexpress endothelial lineage markers such as VEGFR-2 and AC133 and have the capacity to differentiate into adherent endothelial cells and to form cordlike structures in Matrigel. ${ }^{80,87}$

Kamihata et al. ${ }^{88}$ and Shintani et al. ${ }^{89}$ have shown that bone marrow mononuclear cells not only contain EPC but also 
angiogenic factors and cytokines and that implantation of bone marrow mononuclear cells into ischemic tissues augments collateral vessel formation.

Elsheikh et al. ${ }^{81}$ have shown that peripheral blood monocytes $\mathrm{CD}_{14}{ }^{+}$and VEGFR-2 ${ }^{+}$exhibited the potential to differentiate in vitro into cells with endothelial characteristics. Moreover, these cells transduced by a lentiviral vector driving expression of green fluorescent protein (GFP) and transplantation of these cells into ballon-injured femoral arteries of nude mice significantly contributed to efficient re-endothelialization. Rehman et al. ${ }^{78}$ reported that peripheral-blood endothelial-like cells are derived from monocytes/macrophages and secrete angiogenic factors.

Maniotis et al. ${ }^{90}$ described a new model of formation of vascular channels by human melanoma cells and called it 'vasculogenic mimicry' to emphasize the de novo generation of blood vessels without the participation of endothelial cells and independent of angiogenesis. The word 'vasculogenic' was selected to indicate the generation of the pathway de novo and 'mimicry' was used because tumor cell pathways for transporting fluid in tissues were clearly not blood vessels.

Recently, we have demonstrated that multiple myeloma bone marrow TAM exposed to VEGF and FGF-2 develop a number of phenotypic properties similar to those of paired bone marrow endothelial cells, and form capillary-like structures overlapping morphologically those produced by endothelial cells. ${ }^{91}$ At ultrastructural level, multiple myeloma TAMs exhibit numerous cytoplasmic extroversions arranged in tube-like structures and these data suggest that TAMs contribute to build neovessels in multiple myeloma through a vasculogenic mimicry.

TAMs can influence angiogenesis by releasing angiogenic cytokines directly, or indirectly by secreting extracellular matrix-degrading enzymes that release angiogenic factors that have been sequestered by the matrix. TAMs are found in abundance in many tumor types and once the monocytes have entered the tumor environment they are activated by factors peculiar to the tumor microenvironment and migrate toward the areas of hypoxia perhaps following an oxygen gradient or chemokines released by surrounding tumor cells or other inflammatory cells. TAMs then release factors that initiate angiogenesis into the area and their production of extracellular matrix-degrading enzymes facilitates the growth of endothelial cells and loosens the fibrous network of the extracellular matrix thus allowing potentially metastatic tumor cells increased mobility.

With the seemingly central role that TAM could play in tumor angiogenesis, the macrophage itself becomes an appealing target for future antiangiogenic therapeutic strategies through two approaches: (1) compounds that suppress secretion of angiogenic substances by macrophages; and (2) compound that inhibit macrophage infiltration into the tumor mass.

\section{Acknowledgements}

This study was supported by Associazione Italiana per la Ricerca sul Cancro (AIRC, Regional Funds), Milan, the Ministry for Education, the Universities and Research (FIRB 2001, PRIN 2005 and Project CARSO no. 72/2), Rome, and Fondazione Italiana per la Lotta al Neuroblastoma, Genoa, Italy.

\footnotetext{
D Ribatti ${ }^{1}$, B Nico ${ }^{1}$, E Crivellato ${ }^{2}$ and A Vacca ${ }^{3}$ ${ }^{1}$ Department of Human Anatomy and Histology, University of Bari Medical School, Bari, Italy

${ }^{2}$ Department of Medical and Morphological Researches, Anatomy Section, University of Udine Medical School, Udine,
}

${ }^{3}$ Department of Biomedical Sciences and Human Oncology, University of Bari Medical School, Bari, Italy E-mail: ribatti@anatomia.uniba.it

\section{References}

1 Ribatti D, Vacca A, Dammacco F. The role of vascular phase in solid tumor growth: a historical review. Neoplasia 1999; 1: 293-302.

2 Vacca A, Ribatti D. Bone marrow angiogenesis in multiple myeloma. Leukemia 2006; 20: 193-199.

3 Ribatti D, Nico B, Crivellato E, Roccaro AM, Vacca A. The history of the angiogenic switch concept. Leukemia 2007; 21: 44-52.

4 Paget S. The distribution of secondary growths in cancer of the breast. Lancet 1889; i: 571-573.

5 Ribatti D, Mangialardi G, Vacca A. Stephen Paget and the 'seed and soil' theory of metastatic dissemination. Clin Exp Med 2006; 6: 145-149.

6 Ross JA, Auger MJ. The biology of the macrophage. In: Nurke B, Lewis CE (eds), The Macrophage, 2nd edn. Oxford University Press: Oxford, 2002, pp 45-77.

7 Tauber Al, Chernyak L. Metchnikoff and the Origins of Immunology: From Metaphor to Theory. Monographs on the History and Philosophy of Biology. Oxford University Press: New York, 1991, pp 1-155.

8 Sica A, Schioppa T, Mantovani A, Allavena P. Tumour-associated macrophages are a distinct M2 polarised population promoting tumour progression: potential targets of anti-cancer therapy. Eur J Cancer 2006; 42: 717-727.

9 Virchow R. Die Krankenaften Geschwulste. August Hirschwald: Berlin, 1863, pp 1-255.

10 Dvorak HF. Tumors: wounds than not heal. Similarities between tumor stroma generation and wound healing. N Engl J Med 1986; 315: 1650-1659.

11 Graves DT, Valente AJ. Monocyte chemotactic proteins from human tumor cells. Biochem Pharmacol 1991; 41: 331-337.

12 Bottazzi B, Polentarutti N, Acero R, Balsari A, Boraschi D, Ghezzi $\mathrm{P}$ et al. Regulation of the macrophage content of neoplasms by chemoattractants. Science 1983; 220: 210-212.

13 Matsushima K, Larsen CG, Dubois GC, Oppenheim JJ. Purification and characterization of a novel monocyte chemotactic and activating factor produced by a human myelomonocytic cell line. J Exp Med 1999; 169: 1485-1490.

14 Yoshimura T, Robinson EA, Tanaka S, Appella E, Kuratsu J, Leonard EJ. Purification and amino acid analysis of two human glioma-derived monocyte chemoattractants. J Exp Med 1989; 169: 1449-1459.

15 Marumo T, Schini-Kert VB, Busse R. Vascular endothelial growth factor activates nuclear factor-kappa B and induces monocyte chemoattractant protein-1 in bovine retinal endothelial cells. Diabetes 1999; 48: 1131-1137.

16 Lakshminarayanan V, Lewallen M, Frangogiannis NG, Evans AJ, Wedin KE, Michael LH et al. Reactive oxygen intermediates induce monocyte chemotactic protein-1 in vascular endothelium after brief ischemia. Am J Pathol 2001; 159: 1301-1311.

17 Ueno T, Toi M, Saji H, Muta M, Bando $H$, Kuroi $K$ et al. Significance of macrophages chemoattractant protein-1 in macrophage recruitment, angiogenesis and survival in human breast cancer. Clin Cancer Res 2000; 6: 3282-3289.

18 Goede V, Brogelli L, Ziche M, Augusting HG. Induction of inflammatory angiogenesis by monocyte chemoattractant protein-1. Int J Cancer 1999; 82: 765-770.

19 Bingle L, Brown NJ, Lewis CE. The role of tumor-associated macrophages in tumor progression: implications for new anticancer therapies. J Pathol 2002; 196: 254-265.

20 Varney ML, Olsen KJ, Mosley RL, Bucana CD, Talmadge JE, Singh RK. Monocyte/macrophage recruitment, activation and differentiation modulate interleukin-8 production: a paracrine role of tumor-associated macrophages in tumor angiogenesis. In Vivo 2002; 16: 471-477.

21 Liss C, Fekete MJ, Hasina R, Lam CD, Lingen MW. Paracrine angiogenic loop between head-and-neck squamous-cell carcinomas and macrophages. Int J Cancer 2001; 93: 781-785. 
22 Locati M, Deuschle U, Massardi ML, Martinez FO, Sironi M, Sozzani $\mathrm{S}$ et al. Analysis of the gene expression profile activated by the CC chemokine ligand 5/RANTES and the lipopolysaccharide in human monocytes. J Immunol 2002; 168: 3557-3562.

23 Aznenshtein E, Luboshits G, Shina S, Neumark E, Shabbazian D, Weil $\mathrm{M}$ et al. The CC chemokine RANTES in breast carcinoma progression: regulation of expression and potential mechanisms of promalignant activity. Cancer Res 2002; 62: 1093-1102.

24 Dorsch M, Hock H, Kunzendorf U, Diamantstein T, Blankenstein T. Macrophage colony-stimulating factor gene transfer into tumor cells induces macrophage infiltration but not tumor suppression. Eur J Immunol 1993; 23: 186-190.

25 Heike Y, Sone S, Yano S, Seimiya H, Tsuruo T, Ogura T. M-CSF gene transduction in multidrug-resistant human cancer cells to enhance anti-P-glycoprotein antibody-dependent macrophagemediated cytotoxicity. Int J Cancer 1993; 54: 851-857.

26 Lin EY, Nguyen AV, Russell RG, Polard JW. Colony-stimulating factor-1 promotes progression of mammary tumors to malignancy. J Exp Med 2001; 193: 727-740.

27 Kacinski BM. CSF-1 and its receptor in ovarian, endometrial and breast cancer. Ann Med 1995; 27: 79-85.

28 Tang R, Beuvon F, Ojeda M, Mossseri V, Pouillart P, Lidereau R. Anti-colony-stimulating factor-1 antibody staining in primary breast adenocarcinomas correlates with marked inflammatory cell infiltrates and prognosis. J Natl Cancer Inst 1994; 86: 120-126.

29 Clauss M, Gerlach M, Gerlach H, Brett J, Wang F, Familletti PC et al. Vascular permeability factor: a tumor-derived polypeptide that induces endothelial cell and monocyte procoagulant activity, and promotes monocyte migration. J Exp Med 1990; 172: 1535-1545.

30 Leek RD, Hunt NC, Landers RJ, Lewis CE, Royds JA, Harris AL. Macrophage infiltration is associated with VEGF and EGFR expression in breast cancer. J Pathol 2000; 190: 430-436.

31 Baird A, Mormède $\mathrm{P}$, Bohlen P. Immunoreactive fibroblast growth factor in cells of peritoneal exudate suggests its identity with macrophage-derived growth factor. Biochem Biophys Res Commun 1985; 126: 358-364.

32 Joseph-Silverstein J, Moscatelli D, Rifkin DB. The development of quantitative RIA for basic fibroblast growth factor using polyclonal antibodies against the 157 amino acid form of human bFGF. The identification of bFGF in adherent elicited murine peritoneal macrophages. J Immunol Methods 1988; 110: 183-192.

33 Matdess DK, Raines EW, Sakariassen KS, Assoian AK, Sporn MB, Bell Gl et al. Induction of transforming growth factor- $\alpha$ in activated human alveolar macrophages. Cell 1988; 53: 285-293.

34 Rappolle DA, Mark D, Banda MJ, Werb Z. Wound macrophages express TGF- $\alpha$ and other growth factors in vivo: analysis by mRNA phenotyping. Science 1988; 241: 708-712.

35 Assoian RK, Fleurdelys BE, Stevenson HC, Miller PJ, Matdes DK, Raines EW et al. Expression and secretion of type $\beta$ transforming growth factor by activated human macrophages. Proc Natl Acad SCi USA 1987; 84: 6020-6024.

36 Berse B, Brown LF, Van de Water L, Dvorak HF, Senger DR. Vascular permeability factor (vascular endothelial growth factor) gene is expressed differentially in normal tissues, macrophages, and tumors. Mol Biol Cell 1992; 3: 211-220.

37 Leibovich SJ, Polverini PJ, Shepard HM, Wiseman DM, Shively V, Nusier N. Macrophages-induced angiogenesis is mediated by tumor necrosis factor- $\alpha$. Nature $1987 ;$ 320: $584-588$.

38 Roberts NJ, Prill Jr AH, Mann TN. Interleukin 1 and interleukin 1 inhibitor production by human macrophages exposed to influenza virus or respiratory syncytial virus. Respiratory syncytial virus is a potent inducer of inhibitory activity. J Exp Med 1986; 163: 511-519.

39 Koch AE, Polverini PJ, Kunkel SL, Harlow LA, Di Petro LA, Elner $\mathrm{VM}$ et al. Interleukin-8 as a macrophage-derived mediator of angiogenesis. Science 1992; 258: 1798-1801.

40 Seo KH, Ko HM, Choi JH, Jung HH, Chun YH, Choi IW et al. Essential role for platelet-activating factor-induced NF- $\mathrm{BB}$ activation in macrophage-derived angiogenesis. Eur J Immunol 2004; 34: 2129-2137.

41 Martinet Y, Bitterman PB, Mornex JF, Grotendorst GR, Martin GR, Crystal RG. Activated human monocytes express the C-sis protooncogene and release a mediator showing PDGF-like activity. Nature 1986; 319: 158-160.
42 Sullivan R, Gans PJ, Mc Carroll LA. The synthesis and secretion of granulocyte-monocyte colony-stimulating activity (CSA) by isolated human monocytes: kinetics of the response to bacterial endotoxin. J Immunol 1982; 130: 800-807.

43 Hotchkiss KA, Ashton AW, Klein RS, Lenzi ML, Zhu GH, Schwartz EL. Mechanisms by which tumor cells and monocytes expressing the angiogenic factor thymidine phosphorylase mediate human endothelial cell migration. Cancer Res 2003; 63: 527-533.

44 Vicari AP, Caux C. Chemokines in cancer. Cytokine Growth Factor Rev 2002; 13: 143-154.

45 Di Pietro LA, Polverini PJ. Angiogenic macrophages produce the angiogenic inhibitor thrombospondin-1. Am J Pathol 1993; 143: 678-684.

46 Inoue Y, Najkayama Y, Mingawa N, Katsuki T, Nagashima N, Matsumoto $\mathrm{K}$ et al. Relationship between interleukin-12-expressing cells and antigen-presenting cells in patients with colorectal cancer. Anticancer Res 2005; 25: 3541-3546.

47 Belardelli F, Ferrantini M. Cytokines as a link between innate and adaptive antitumor immunity. Trends Immunol 2002; 23: 201-208.

48 Kerkela E, Ala-Aho R, Jeskanen L, Rechardt O, Grenman R, Shapiro SD et al. Expression of human macrophage metalloelastase (MMP-12) by tumor cells in skin cancer. J Invest Dermatol 2000; 114: 1113-1119.

49 Sunderkotter C, Goebeler M, Schulze-Osthoff K, Bhardwaj R, Sorg C. Macrophage-derived angiogenesis factor. Pharmacol Ther 1991; 51: 195-216.

50 Lewis CE, Leek R, Harris A, Mc Gee JO. Cytokine regulation of angiogenesis in breast cancer: the role of tumor-associated macrophages. J Leukoc Biol 1995; 57: 747-751.

51 Klimp AH, Hollema $H$, Kempinga $C$, van AG, de Vries EG, Daemen T. Expression of cyclooxygenase-2 and inducible nitric oxide synthase in human ovarian tumors and tumor-associated macrophages. Cancer Res 2001; 61: 7305-7309.

52 Giraudo E, Inoue M, Hanahan D. An amino-bisphosphonate targets MMP-9-expressing macrophages and angiogenesis to impair cervical carcinogenesis. J Clin Invest 2004; 114: 623-633.

53 Talks KL, Tyrley H, Gatter KC, Maxwell PH, Pugh CW, Ratcliffe PJ et al. The expression and distribution of the hypoxia-inducible factors HIF-1alpha and HIF-2alpha in normal human tissues, cancers, and tumor-associated macrophages. Am J Pathol 2000; 157: 411-421.

54 Leek RD, Landers RJ, Harris AL, Lewis CE. Necrosis correlates with high vascular density and focal macrophage infiltration in invasive carcinoma of the breast. Br J Cancer 1999; 79: 991-995.

55 White JR, Harris RA, Lee SR, Craigon MH, Binley K, Price T et al. Genetic amplification of the transcriptional response to hypoxia as a novel means of identifying regulators of angiogenesis. Genomics 2004; 83: 1-8.

56 Lewis JS, Landers RJ, Underwood JC, Harris AL, Lewis CE. Expression of vascular endothelial growth factor by macrophages is up-regulated in poorly vascularized areas of breast carcinomas. J Pathol 2000; 192: 150-158.

57 Burke B, Giannoudis A, Corke KP, Gill D, Wells M, ZieglerHeitbrock L et al. Hypoxia-induced gene expression in human macrophages: implications for ischemic tissues and hypoxiaregulated gene therapy. Am J Pathol 2003; 163: 1233-1243.

58 Nishizuka I, Ichikawa Y, Ichikawa T, Kamiyama M, Hasegawa S, Momiyama $\mathrm{N}$ et al. Matrylisin stimulates DNA synthesis of cultured vascular endothelial cells and induce angiogenesis in vivo. Cancer Lett 2001; 173: 175-182.

59 Bingle L, Lewis CE, Corke K, Reed MW, Brown NJ. Macrophages promote angiogenesis in human breast tumour spheroids in vivo. Br J Cancer 2005; 94: 101-107.

60 Evans R. Effect of X-irradiation on host cell infiltration and growth of murine fibrosarcoma. Br J Cancer 1977; 35: 557-566.

61 Evans R. The effect of azathioprine on host-cell infiltration and growth of a murine fibrosarcoma. Int J Cancer 1977; 20: 120-128.

62 Mostafa LK, Jones DB, Wright DH. Mechanism of the induction of angiogenesis by human neoplastic lymphoid tissue: studies on the chorioallantoic (CAM) of the chick embryo. J Pathol 1980; 132: 91-105.

63 Mostafa LK, Jones DB, Wright DH. Mechanism of the induction of angiogenesis by human neoplastic lymphoid tissue: studies 
employing bovine aortic endothelial cells in vitro. J Pathol 1980; 132: 207-216.

64 Stenzinger W, Bruggen J, Macher E, Sorg C. Tumor angiogenic activity (TAA) production in vitro and growth in the nude mice by human malignant melanoma. Eur J Cancer Clin Oncol 1982; 19: 649-656.

65 Polverini PJ, Leibovich SJ. Induction of neovascularization in vivo and endothelial proliferation in vitro by tumor associated macrophages. Lab Invest 1984; 51: 635-642.

66 Polverini PJ, Leibovich SJ. Effect of macrophage depletion on growth and neovascularization of hamster buccal pouch carcinomas. J Oral Pathol 1987; 16: 436-441.

67 Lin EY, Li JF, Gnatovskiy L, Deng Y, Zhu L, Grzesik DA et al. Macrophage regulate the angiogenic switch in a mouse model of breast cancer. Cancer Res 2006; 66: 11238-11246.

68 De Palma M, Venneri MA, Galli R. Tie2 identifies a hematopoietic lineage of proangiogenic monocytes required for tumor vessel formation and a mesenchymal population of pericyte progenitors. Cancer Cell 2005; 8: 211-226.

69 Leek RD, Lewis CE, Whitehouse R, Greenall M, Clarke J, Harris AL. Association of macrophage infiltration with angiogenesis and prognosis in invasive breast carcinoma. Cancer Res 1996; 56 4625-4629.

70 Leek RD, Harris AL. Tumor-associated macrophages in breast cancer. I Mammary Gland Biol Neoplasia 2002; 7: 177-189.

71 Makitie T, Summanen P, Tarkkanen A, Kivela T. Tumor infiltrating macrophages (CD68(+) cells) and prognosis in malignant uveal melanoma. Invest Ophthalmol Vis Sci 2001; 42: 1414-1421.

72 Nishie A, Ono M, Shono T, Fukushi I, Otsubo M, Onoue $\mathrm{H}$ et al. Macrophage infiltration and heme oxygenase- 1 expression correlate with angiogenesis in human gliomas. Clin Cancer Res 1999; 5 : 1107-1113

73 Koide N, Nishio A, Sato T, Sugiyama A, Miyagawa S. Significance of macrophage chemoattractant protein-1 expression and macrophage infiltration in squamous cell carcinoma of the esophagus. Am J Gastroenterol 2004; 99: 1667-1674.

74 Hanada T, Nakagawa M, Emoto A, Nomura T, Nasu N, Nomura Y. Prognostic value of tumor-associated macrophage count in human bladder cancer. Int J Urol 2000; 7: 263-269.

75 Lissbrandt IF, Stattin P, Wilkstrom P, Damber JE, Egevad L, Bergh A Tumor associated macrophages in human prostate cancer: relation to clinicopathological variables and survival. Int J Oncol 2000; 17 445-451.

76 Mantovani A, Sozzani S, Locati M, Allavena P, Sica A. Macrophage polarization: tumor associated macrophages as a paradigm for polarized M2 mononuclear phagocytes. Trends Immunol 2002; 23: $549-555$

77 Fernandez Pujol B, Lucibello FC, Gehling UM, Lindemann K, Weidner $\mathrm{N}$, Zuzarte ML et al. Endothelial-like cells derived from human CD14 positive monocytes. Differentiation 2000; 65 287-300.

78 Rehman J, Li J, Orschell CM, March KL. Peripheral blood 'endothelial progenitor cells' are derived from monocytes/ macrophages and secrete angiogenic growth factors. Circulation 2003; 107: 1164-1169.

79 Urbich C, Heeschen C, Aicher A, Dernbach E, Zeiher AM, Dimmeler S. Relevance of monocytic features for neovascularization capacity of circulating endothelial progenitor cells. Circulation 2003; 108: 2511-2516.

80 Schmeisser A, Garlichs CD, Zhang H, Eskafi S, Graffy C, Ludwig J et al. Monocytes coexpress endothelial and macrophagocytic lineage markers and form cord-like structures in Matrigel under angiogenic conditions. Cardiovasc Res 2001; 49: 671-680.

81 Elsheikh E, Uzunel M, He Z, Holgersson J, Nowak G, SumitranHolgersson S. Only a specific subset of human peropheral-blood monocytes has endothelial-like functional activity. Blood 2005; 106: $2347-2355$.

82 Fujiyama S, Amano K, Uehira K, Yoshida M, Nishiwaki Y, Nozawa Y et al. Bone marrow monocyte lineage cells adhere on injured endothelium in a monocyte chemoattractant protein-1-dependent manner and accelerate neoendothelization as endothelial progenitor cells. Circ Res 2003; 93: 980-989.

83 Iba O, Matsubara H, Nozawa Y, Fujiyama S, Amano K, Mori Y et al. Angiogenesis by implantation of peripheral blood mononuclear cells and platelets into ischemic limbs. Circulation 2002; 106: 2019-2025.

84 Nowak G, Karrar A, Holmen C, Nava S, Uzunel M, Hultenby K et al. Expression of vascular endothelial growth factor receptor-2 or Tie-2 on peripheral blood cells defines functionally competent populations capable of reendothelialization. Circulation 2004; 110: 3699-3702.

85 Zhao Y, Glesne D, Huberman E. A human peripheral blood monocyte-derived subset acts as pluripotent stem cells. Proc Natl Acad Sci USA 2003; 100: 2426-2431.

86 Kalka C, Masuda H, Takahashi T, Kalka-Moll WM, Silver M, Kearney $\mathrm{M}$ et al. Transplantation of ex vivo expanded endothelial progenitor cells for therapeutic neovascularization. Proc Natl Acad Sci USA 2000; 97: 3422-3427.

87 Schmeisser A, Graffy C, Daniel WG, Strasser RH. Phenotypic overlap between monocytes and vascular endothelial cells. Adv Exp Med Biol 2003; 522: 59-74.

88 Kamihata $\mathrm{H}$, Matsubara $\mathrm{H}$, Nishiue T, Fujiyama S, Tsutsumi $\mathrm{Y}$, Ozono $\mathrm{R}$ et al. Implantation of bone marrow mononuclear cells into ischemic myocardium enhances collateral perfusion and regional function via side supply of angioblasts, angiogenic ligands, and cytokines. Circulation 2001; 104: 1046-1052.

89 Shintani S, Murohara T, Ikeda H, Ueno T, Sasaki K, Duan J et al. Augmentation of postnatal neovascularization with autologous bone marrow transplantation. Circulation 2001; 103: 895-897.

90 Maniotis AJ, Folberg R, Hess A, Seftor EA, Gardner LM, Peer J et al. Vascular channel formation by human melanoma cells in vivo and in vitro: vasculogenic mimicry. Am J Pathol 1999; 155: 739-752.

91 Scavelli C, Nico B, Cirulli T, Ria R, Di Pietro G, Mangieri D et al. Vasculogenic mimicry by bone marrow macrophages in patients with multiple myeloma. Oncogene 2007 (accepted for publication). 